\title{
SETOR EXTERNO E ECONOMIA INTERNACIONAL \\ O crescimento da China e seus impactos sobre a economia mineira
}

\author{
Gilberto Libânio*
}

RESUMO - O presente trabalho busca discutir a importância do setor externo no desempenho recente da economia mineira. Em particular, procura examinar em que medida a economia do estado tem sido afetada pelo expressivo crescimento da China e sua maior participação no comércio mundial nos últimos anos. A hipótese central deste trabalho é de que o "efeito China" tem contribuído positivamente para o desempenho de nossa economia, devido principalmente à crescente demanda chinesa por produtos minerais e a conseqüente elevação dos preços destas commodities no mercado internacional. Entretanto, apesar dos benefícios de curto prazo, tal estratégia de desenvolvimento aprofunda o caráter primárioexportador da economia mineira e, portanto, agrava os problemas decorrentes deste padrão de especialização.

Palavras-chave: China. Minas Gerais. Comércio exterior. Padrão de especialização.

\section{INTRODUÇÃO}

A China tem se tornado um dos grandes destaques no cenário econômico global nos últimos anos, em virtude de suas expressivas taxas de crescimento e de seu peso crescente no comércio internacional. $\mathrm{O}$ crescimento da importância da China decorre não apenas de seu desempenho, mas também do seu porte: o país tem a maior população do planeta - cerca de 1,3 bilhões de habitantes - e atualmente a quarta maior economia, com um PIB de aproximadamente US\$ 3 trilhões. Ademais, já ocupa o terceiro lugar em termos de volume de comércio internacional, com cerca de $6 \%$ do total transacionado mundialmente. Estas características fazem com que o crescimento chinês tenha implicações e impactos globais bastante distintos de outras experiências bem sucedidas de crescimento econômico na segunda metade do século XX, como os casos de Japão, Coréia do Sul e outros "tigres asiáticos". Neste sentido, o grande interesse que a emergência da China desperta atualmente deriva também de seu ineditismo, visto que não se encontram na história econômica recente outros exemplos de igual magnitude.

O crescimento chinês e sua presença maciça no comércio internacional têm causado intensa preocupação e impactos diferenciados sobre as economias de países desenvolvidos e

\footnotetext{
* Doutor em Economia pela University of Notre Dame, EUA (2006). Professor Adjunto do Departamento de Ciências Econômicas e do CEDEPLAR/UFMG. Endereço eletrônico: gilberto@cedeplar.ufmg.br
} 
em desenvolvimento. Tais impactos podem ser resumidos em duas frentes. Por um lado, a grande competitividade dos produtos manufaturados chineses no mercado mundial representa um desafio e uma ameaça a países cuja pauta de exportações seja baseada neste tipo de produto. Por outro, a expressiva demanda da China por commodities tem provocado substancial elevação de seus preços no mercado internacional e tem beneficiado países exportadores de produtos primários. Em última instância, os efeitos da expansão chinesa dependem do padrão de especialização setorial das economias, sendo que os países mais penalizados são aqueles cujas estruturas produtivas competem diretamente com a China no comércio mundial.

Esta nota procura examinar as implicações do crescimento chinês para economia de Minas Gerais. A hipótese central do trabalho é de que o "efeito China" tem contribuído positivamente para o desempenho de nossa economia, devido principalmente à crescente demanda chinesa por produtos minerais e a conseqüente elevação dos preços destas commodities no mercado internacional. Neste sentido, os argumentos que serão colocados aqui seguem a idéia de que a economia de Minas Gerais apresenta um padrão de especialização com alto grau de complementaridade em relação à China e, portanto, tem recebido impactos positivos em seus principais setores exportadores, associados à produção agrícola e à extração mineral. Argumentar-se-á, entretanto, que apesar dos benefícios de curto prazo, nossa atual estratégia de desenvolvimento aprofunda o caráter primário-exportador da economia mineira e, portanto, agrava os problemas decorrentes deste padrão de especialização.

O restante do texto está dividido em mais três seções. A próxima seção descreve o desempenho recente da China e seu padrão de especialização setorial, assim como os efeitos de sua expansão sobre as economias da América Latina e, em particular, do Brasil. A seção três trata especificamente da economia mineira, e busca mostrar como a China tem afetado positivamente seu desempenho recente. Ademais, discute alguns dos problemas decorrentes do caráter primário-exportador de nossa economia, associados principalmente ao conceito de “doença holandesa". Por fim, na última seção, são resumidos os argumentos e resultados centrais do artigo e são apresentadas algumas considerações finais.

\section{A CHINA NO CENÁRIO ECONÔMICO INTERNACIONAL}

A economia chinesa tem crescido a uma taxa média anual de quase $10 \%$ nas últimas três décadas. Isto significa que o PIB da China é atualmente cerca de 12 vezes maior que seu valor ao final dos anos setenta. Este expressivo crescimento tem sido baseado 
fundamentalmente no dinamismo do setor industrial, que cresceu 18 vezes entre 1978 e 2006, o que corresponde a uma taxa média de crescimento de 12\% ao ano. Em 2006, observa-se que o setor secundário é de fato o setor mais importante da economia da China, representando quase $50 \%$ do $\mathrm{PIB}^{6}$.

Por outro lado, o país tem passado por um processo de abertura comercial e tem elevado substancialmente sua participação no comércio internacional nos últimos anos. As tarifas médias de importação caíram de aproximadamente 40\% no início dos anos noventa para cerca de 6\% atualmente. A inclusão da China na OMC a partir de 2001 reflete sua maior abertura comercial e também contribuiu para alavancar sua inserção como potência comercial global, ao permitir maior acesso de produtos chineses aos mercados internacionais. Entre 2002 e 2006, o volume de exportações da China cresceu a uma média anual de 28\%, enquanto o volume de importações cresceu em média 21\% ao ano (UNCTAD, 2007). Assim, sua participação nas exportações mundiais tem crescido consistentemente ao longo do tempo, passando de 1,5\% em 1980 para 2,5\% em 1995 e atingindo 7\% em 20057.

A expansão da China nos mercados mundiais e sua maior abertura comercial tiveram também como conseqüência um aumento das exportações e importações como proporção do PIB. Em 1990, estes valores eram de 20\% e 15\%, respectivamente. Em 2006, as exportações correspondem a $37 \%$ do PIB, enquanto as importações alcançaram 32\% do PIB. Estes valores colocam a China como uma das economias mais abertas do planeta, principalmente se comparada a outros países de dimensão continental, como Brasil, Estados Unidos, Canadá, cujos fluxos comerciais (exportações + importações) correspondem a menos de 30\% do PIB.

Cabe notar que os dois elementos destacados acima - expressivo crescimento do setor manufatureiro e expansão do comércio internacional - não são independentes. De fato, boa parte do crescimento industrial pode ser explicada pelas vendas externas do país. Durante os últimos anos, quase $90 \%$ das exportações da China concentram-se em três setores industriais: equipamento e material de transporte, bens manufaturados e outras manufaturas. Suas importações são também baseadas nestes setores, embora nos últimos cinco anos tem-se observado crescente participação de combustíveis e lubrificantes, bem como de produtos primários em geral. Dado o expressivo crescimento de setores intensivos em commodities, a China tem sido a principal responsável pela expansão da demanda mundial por produtos como minério de ferro, petróleo, cobre e soja, o que tem beneficiado países exportadores de

\footnotetext{
${ }^{6}$ Por sua vez, os setores primário e terciário correspondem, respectivamente, a $12 \%$ e 41\% do PIB.

${ }^{7}$ Fonte: World Development Indicators Database.
} 
matérias-primas, tanto pelo aumento dos volumes exportados, como pela elevação generalizada dos preços de commodities no mercado internacional (ver tabela 1).

TABELA 1 - PREÇOS DE COMMODITIES NO MERCADO INTERNACIONAL - (VARIAÇÃO \% 2002/2006)

\begin{tabular}{|c|c|c|}
\hline & Descrição & Variação \% (2002-2006) \\
\hline & Índice geral & 88,8 \\
\hline & Minerais & 219,9 \\
\hline & Alimentos e bebidas & 48,4 \\
\hline & Matérias-primas agrícolas & 62,3 \\
\hline & Petróleo cru & 157,3 \\
\hline
\end{tabular}

A expansão da China tem contribuído não apenas para elevar os preços das commodities, mas também para o declínio nos preços de manufaturas, gerando, uma vez mais, uma dinâmica de termos de troca desfavorável a países cuja pauta de exportação seja concentrada em manufaturas.

O crescimento chinês e sua presença maciça no comércio internacional têm causado grande interesse, no que se refere a seus impactos sobre outras economias emergentes. Particularmente, dado o foco deste artigo, cabe destacar os impactos da expansão chinesa sobre os países da América Latina, que têm sido objeto de diversos trabalhos recentes. Em linhas gerais, tais impactos obedecem aos mesmos condicionantes associados ao padrão de especialização, ou seja, os efeitos da expansão chinesa dependem do padrão de especialização setorial das economias, sendo que os países mais penalizados são aqueles cujas estruturas produtivas competem diretamente com a China no comércio mundial.

Para os países da América Latina, observa-se grande diversidade em relação a este aspecto. Em um extremo, encontra-se o México, com um elevado grau de competição com a China, devido principalmente às exportações de manufaturas para o mercado norteamericano. Em outro extremo, temos países como Paraguai, Venezuela, Bolívia, Paraguai e Chile, cujas pautas de exportação são mais fortemente concentradas em commodities agrícolas ou minerais e que, portanto, apresentam padrão de especialização bastante distinto em relação à China. De modo geral, a situação da maioria dos países da América Latina é bastante favorável, sugerindo que a expansão chinesa tende a trazer mais benefícios do que custos para a região como um todo.

Quanto ao Brasil, sua posição é intermediária, ou seja, a competição com a China não é tão alta, mas ainda assim preocupante. Tal resultado decorre do fato de que nossa pauta de exportação é caracterizada por elevado grau de diversificação, com presença importante tanto de manufaturas quanto de commodities. 
De modo geral, a experiência recente tem mostrado que o Brasil tem sido beneficiado pela expansão da China no cenário mundial. Apesar da sobrevalorização cambial observada nos últimos dois anos, as exportações brasileiras têm atingido recordes históricos no período, contribuindo para a elevação da demanda interna e taxas de crescimento relativamente altas. Particularmente, as exportações brasileiras para a China quadruplicaram entre 2002 e 2007, e hoje representam cerca de 7\% do total de exportações do país.

A evolução recente da economia brasileira segundo setores de atividade pode ser vista no gráfico 1. Observa-se que o crescimento da economia nos últimos anos tem sido puxado principalmente pelo setor agropecuário e pela indústria extrativa mineral, enquanto que o setor industrial como um todo tem crescido abaixo da média global da economia. Alguns setores da indústria têm sido particularmente mais afetados pela concorrência com produtos chineses, tanto pela concorrência no mercado doméstico quanto pela ameaça a mercados de exportação. Segundo a CNI (2007), os setores que têm sofrido concorrência mais acirrada dos produtos chineses no mercado brasileiro são têxteis, vestuário, calçados, equipamentos hospitalares e de precisão, enquanto que, nos mercados internacionais, os setores mais ameaçados são mobiliário, madeira, calçados, vestuário e couro (CNI, 2007).

GRÁFICO 1 - EVOLUÇÃO DO PIB POR SETORES DE ATIVIDADE (ÍNDICE: 1996=100) - BRASIL (1996-2007)

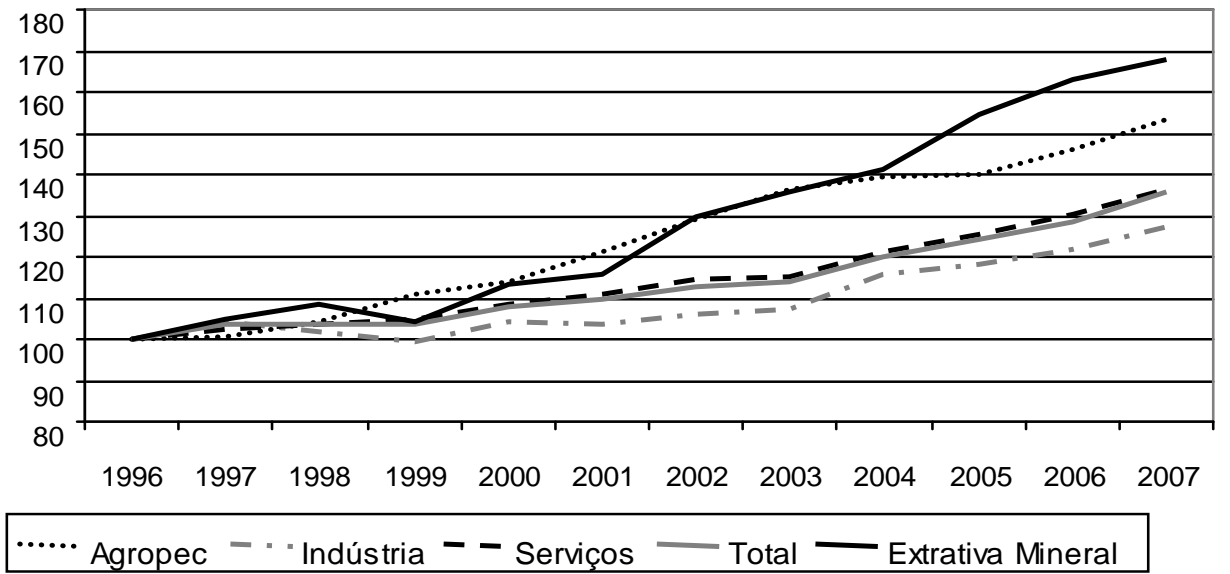

FONTE: IBGE.

\section{O "EFEITO CHINA" EM MINAS GERAIS}

A economia de Minas Gerais esteve historicamente associada, em maior ou menor grau, à produção e exportação de produtos primários agrícolas ou minerais, como ouro, pedras preciosas, café e leite. Este caráter primário-exportador ainda permanece como um dos aspectos mais marcantes da economia mineira. Dentre os quinze maiores setores exportadores do Estado, oito podem ser considerados bem primários ou semi-manufaturas 
baseadas em recursos naturais. Ademais, em 2007, 40\% das exportações de Minas Gerais correspondem a apenas duas commodities: minério de ferro e café. A principal exceção a este perfil é a exportação de automóveis, tratores e autopeças, que aparece como o terceiro setor exportador mais expressivo no Estado, em virtude principalmente da fábrica da FIAT Automóveis. O gráfico 2 mostra os principais setores exportadores de Minas Gerais em 2007. GRÁFICO 2 - PRINCIPAIS PRODUTOS EXPORTADOS - MINAS GERAIS (2007)

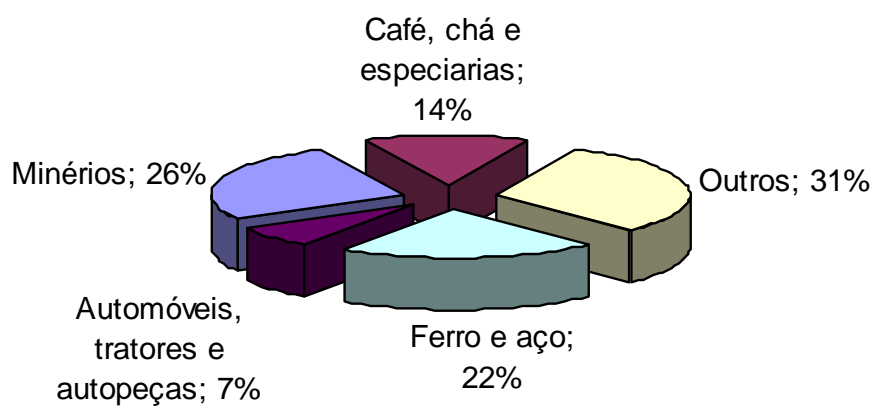

FONTE: SECEX.

O padrão de especialização primário-exportador da economia mineira reflete-se também no perfil das maiores empresas exportadoras do Estado. As duas maiores exportadoras em 2006 (CVRD e MBR) estão no setor de extração mineral. Ademais, dentre as dez maiores empresas, sete estão no setor metalúrgico-siderúrgico e uma no setor de papel e celulose. Apenas a FIAT automóveis, terceira maior em valor exportado no Estado, escapa ao perfil de produção de commodities minerais ou semi-manufaturas baseadas em recursos minerais.

Devido ao este padrão de especialização, a economia de Minas Gerais apresenta elevado grau de complementaridade em relação à China e, por esta razão, tem sido fortemente beneficiada pela maior inserção daquele país na economia global. Neste sentido, Minas Gerais apresenta-se em posição bem mais favorável que a economia brasileira como um todo, visto que boa parte dos setores que mais se beneficiam do comércio com a China têm forte presença no Estado, ao passo que alguns dos setores mais prejudicados não têm grande relevância na economia mineira.

Esta posição mais favorável da economia mineira em termos de padrão de especialização é um elemento crucial para entender seu desempenho recente, resumido nos gráficos que seguem. O gráfico 3 apresenta a evolução do PIB por setores de atividade. Cabe notar a expressiva expansão da indústria extrativa mineral desde 2001, ano de admissão da China na OMC. 
GRÁFICO 3 - PIB POR SETORES DE ATIVIDADE (INDICE 1996=100) - MINAS GERAIS (1996-2007)

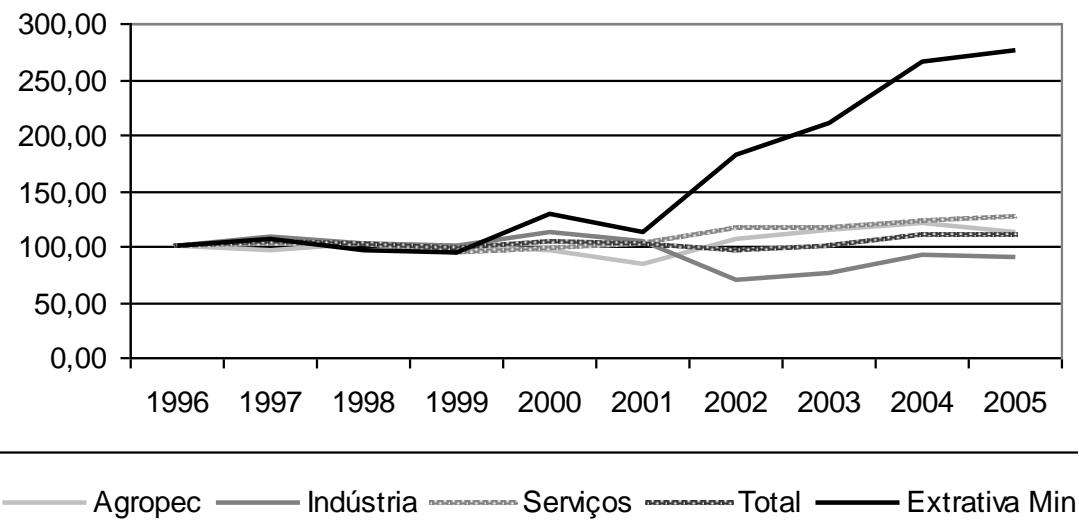

FONTE: IBGE.

A correlação entre o crescimento da China e o desempenho do setor de mineração em Minas Gerais fica ainda mais claro analisando-se o gráfico 4, que mostra a trajetória das exportações do Brasil e de Minas Gerais para a China. No caso de Minas Gerais, observa-se expressiva expansão das exportações para a China nos últimos anos. Entre 2001 e 2007, as exportações do Estado para a China cresceram seis vezes. Em 2007, a China passou a ser o principal destino para as exportações de Minas Gerais (15\% do total exportado pelo estado). Cabe notar que o minério de ferro responde por $80 \%$ das nossas exportações para a China.

GRÁFICO 4 - EXPORTAÇÕES PARA CHINA - BRASIL E MINAS GERAIS (1996-2007)

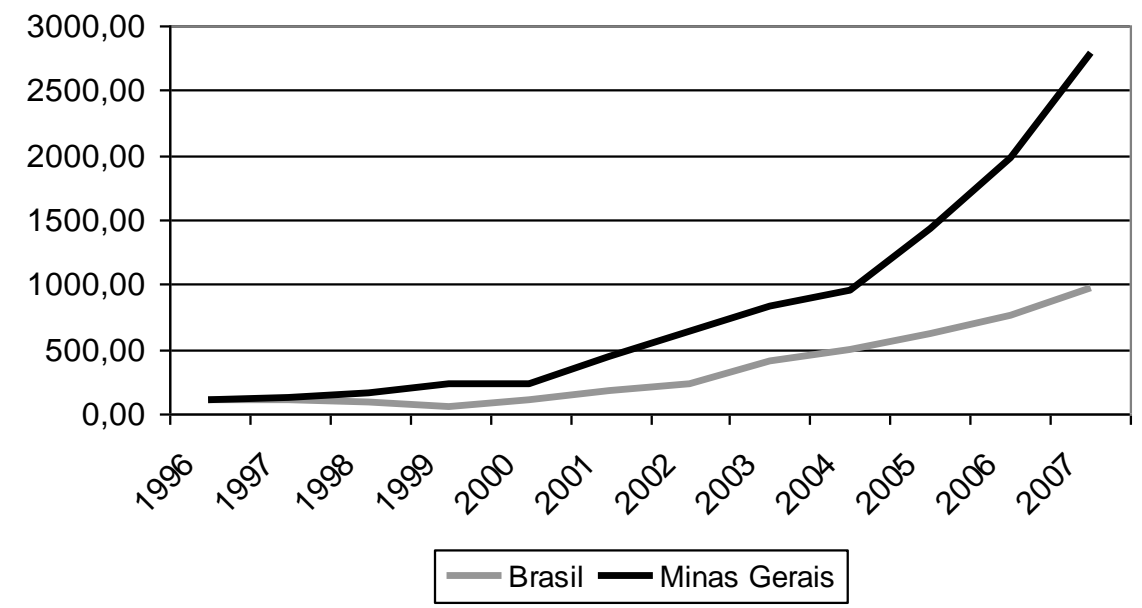

FONTE: SECEX.

Embora a economia de Minas Gerais tenha claramente se beneficiado da expansão da China nos últimos anos, é importante salientar que nossa atual estratégia de desenvolvimento aprofunda o caráter primário-exportador de nossa economia, o que pode significar taxas de crescimento pouco satisfatórias a longo prazo. Como destacado por uma vasta literatura teórica e empírica a respeito da relação entre padrão de especialização e crescimento, os países que apresentam taxas de crescimento mais expressivas são aqueles que conseguem 
desenvolver rapidamente seu setor industrial, principalmente com a especialização em setores de maior dinamismo tecnológico e com maiores externalidades em P\&D e outras formas de spillovers.

Ademais, o grande dinamismo do setor de commodities traz ainda alguns problemas não desprezíveis. Em primeiro lugar, os significativos danos ao meio ambiente provocados pela atividade mineradora. Em segundo lugar, o fato de que os preços de commodities flutuam de forma bastante intensa nos mercados internacionais, trazendo certo grau de instabilidade a economias que têm nestes produtos uma fonte importante de recursos. Por fim, cabe notar que, na maioria dos casos, tais setores são intensivos em capital, o que significa que o ritmo de geração de postos de trabalho não acompanha a expansão do valor agregado no setor.

\section{CONSIDERAÇÕES FINAIS}

Este trabalho procura examinar brevemente as implicações do crescimento chinês para economia de Minas Gerais. A hipótese central do trabalho é de que o "efeito China" tem contribuído positivamente para o desempenho de nossa economia, devido principalmente à crescente demanda chinesa por produtos minerais e a conseqüente elevação dos preços destas commodities no mercado internacional. Neste sentido, os argumentos colocados aqui seguem a idéia de que a economia de Minas Gerais apresenta um padrão de especialização com alto grau de complementaridade em relação à China e, portanto, tem recebido impactos positivos em seus principais setores exportadores, associados à produção agrícola e à extração mineral. Argumenta-se, entretanto, que apesar dos benefícios de curto prazo, a atual estratégia de desenvolvimento aprofunda o caráter primário-exportador da economia mineira e, portanto, agrava os problemas decorrentes deste padrão de especialização.

\section{REFERÊNCIAS}

CNI. Concorrência com produtos da China afeta uma em cada quatro empresas industriais brasileiras. Sondagem Especial CNI, ano 5, n.1, mar. 2007.

IDB. The Emergence of China. Opportunities and Challenges for Latin America and the Caribbean. Cambridge, MA: Harvard University Press, 2006.

IMF. World Economic Outlook. Washington, DC: International Monetary Fund, 2007.

UNCTAD. Trade and Development Report. New York and Geneva: United Nations, 2007. 